\title{
EFFECT OF PROBIOTIC SUPPLEMENTATION ON LIVER FUNCTION AND LIPID STATUS IN RATS
}

\author{
Katarzyna Skrypnik ${ }^{1}$, Paweł Bogdański², Igor Łoniewski ${ }^{3}$, Julita Reguła ${ }^{1}$, \\ Joanna Suliburska ${ }^{1 凶}$ \\ ${ }^{1}$ Institute of Human Nutrition and Dietetics, Poznań University of Life Sciences \\ Wojska Polskiego 31, 60-624 Poznań, Poland \\ 2Department of Education and Obesity Treatment and Metabolic Disorders, Poznan University of Medical Sciences \\ Szamarzewskiego 82/84, 60-569 Poznań, Poland \\ ${ }^{3}$ Department of Biochemistry and Human Nutrition, Pomeranian Medical University \\ Broniewskiego 24, 71-460 Szczecin, Poland
}

\begin{abstract}
Background. High gut microflora quality plays a crucial role in cardiovascular protection and undisturbed liver function. Currently, the most effective methods to ameliorate gut microbiota influence on the host's cardiovascular health state are investigated. Next to low low-density lipoprotein (LDL) and low non-high-density lipoprotein (non-HDL) serum levels, triglycerides (TG) seem to be a new goal of cardioprotective treatment and prevention. Moreover, it has been documented that high serum alanine transaminase (ALT) is a reliable marker of cardiovascular risk. Probiotics are a well proven factor decreasing blood LDL and total cholesterol $(\mathrm{TCH})$ concentrations. However, the effect of probiotics on serum TG and ALT levels remains underinvestigated. The aim of the study was to compare the effect of 6-week-long supplementation with a multispecies probiotic mixture in two doses on body mass, liver function and lipid profile in the rat model.

Material and methods. Thirty 'Wistar' rats were randomly divided into the control group - KK, a group receiving a probiotic in a daily dose of $2.5 \times 10^{9} \mathrm{CFU}(\mathrm{PA})$ and a group receiving a probiotic in a daily dose of $1 \times 10^{10} \mathrm{CFU}(\mathrm{PB})$ for 6 weeks. After 6 weeks body mass, liver mass, serum concentrations of TCH, LDL, high-density lipoprotein (HDL), TG, ALT and aspartate transaminase (AST) were determined.

Results. Neither at baseline nor at the end of the experiment were there any differences in the body mass of rats between all three groups. At the completion of the study the liver mass of the rats was significantly lower in the PA and PB vs. KK group. In group PB a significantly lower serum concentration of TG and ALT compared to the KK group was registered at the end of the trial.

Conclusion. Six-week-long supplementation with multispecies probiotic mixture exerts a favorable and dose-dependent effect on liver function and lipid profile in the rat model and may also have a favorable influence on cardiovascular impairments. Thus, the inclusion of probiotics supplementation in cardiovascular risk management should be considered.
\end{abstract}

Keywords: gut microflora, probiotics, cardiovascular risk, lipid profile, liver function, triglycerides 


\section{INTRODUCTION}

Due to its great importance, human microbiota, with a total mass estimated up to $2 \mathrm{~kg}$ and a number of cells even 10 times greater than the number of human body cells, has been named the "newly discovered organ" (Bianconi et al., 2013; Collado et al., 2016; Dinc et al., 2006; Kverka and Tlaskalová-Hogenová, 2017). Gut microflora has a range of functions: it affects specific and nonspecific immunity, protects against pathogen growth, inhibits gastrointestinal inflammation, and contributes to biotin and vitamin $\mathrm{K}$ production $(\mathrm{He}$ et al., 2016; Skrypnik and Suliburska, 2017; Qiu et al., 2013). Gut bacteria are involved in metabolizing carbohydrates and lipids by the fermentation of undigested carbohydrates, bile acids and sterols, and by the synthesis of hormones regulating fat storage (He et al., 2016). It has recently been proven that unfavorable changes in gut microflora significantly elevate the host's cardiometabolic risk (Ascher and Reinhardt, 2018). Intestinal microbiota preserves the gut epithelial barrier against increased permeability, which leads to leaky gut syndrome (LGS). Leaky gut syndrome contributes to the development of such states as obesity, diabetes, dyslipidemia and atherosclerosis. What is more, recent studies show that LGS is a causative factor of non-alcoholic fatty liver disease (NAFLD), one of the most frequent liver disorders in obesity. Thus, high gut microflora quality rises to play a crucial role in cardiovascular $(\mathrm{CV})$ protection and undisturbed liver function (Bischoff et al., 2014; Houghton et al., 2016; Ierardi et al., 2015). The most effective methods to ameliorate gut microbiota influence on host's health state are currently being investigated.

Dyslipidemia is a well-proven factor of $\mathrm{CV}$ risk and high low-density lipoprotein (LDL) serum concentration has been determined to exert the strongest unfavorable cardiometabolic effect, mainly through the promotion of atherosclerosis. However, recently it has been documented that a high serum level of non-high-density lipoproteins (non-HDL) increases the risk of major cardiovascular events (MACE; i.e. myocardial infarction, stroke, and vascular mortality) in a comparable magnitude in patients with a history of cerebrovascular, coronary artery or polyvascular disease. This parameter, next to the LDL serum level, is postulated to be a secondary target in CV risk management (Nicholls and Scherer, 2015; van den Berg et al., 2016). Moreover, there are many cardiovascular disease (CVD) patients who, despite favorable alterations in their blood lipid profile, still experience $\mathrm{CV}$ events. It has been shown that a high serum concentration of triglycerides (TG), both fasting and nonfasting, is responsible to the greatest extent for this residual $\mathrm{CV}$ risk. Each $1 \mathrm{mmol} / \mathrm{L}$ increase in TG serum concentration is responsible for a $32 \%$ and $76 \%$ increase in CV risk in males and females respectively. An elevated TG blood level identifies patients with a high CV risk after LDL blood level normalization by statin pharmacotherapy. Hence, lowering the TG serum concentration is a new goal of CVD prevention strategies (Nicholls and Scherer, 2015).

Probiotics are live microorganisms exerting a beneficial effect on human health (Skrypnik and Suliburska, 2017). Probiotics support the gastrointestinal (GI) microbiota function in multifaceted mechanisms. They support the intestinal barrier by increasing mucin, defensin and IgA production and by favorably modifying the proinflammatory cytokine and chemokine response. As a consequence, they help counteract LGS and decrease the cardiometabolic risk (Marteau et al., 2013; Sánchez et al., 2017). A further cardioprotective effect of probiotics results from their influence on the blood lipid profile. Probiotics decrease the serum concentration of total cholesterol (TCH) and LDL. This effect was shown even in metabolic syndrome (MS), which is a proven risk factor of premature $\mathrm{CV}$ death, and was accompanied by a body mass fall and a reduction in the serum content of tumor necrosis factor- $\alpha$ (TNF- $\alpha$ ) and interleukin-6 (IL-6; Bernini et al., 2016). These markers of chronic inflammation have also been proven to participate in the pathophysiology of CVD (Li et al., 2017; Tuomisto et al., 2006). However, the effect of probiotics on high-density lipoproteins (HDL) and TG has still not been investigated thoroughly. Recently, it has been documented that the serum concentration of alanine transaminase (ALT), even within normal ranges, is associated with an increased $\mathrm{CV}$ risk (Kong et al., 2008). Taking into consideration the fact that CVD and liver disorders frequently coexist (Kong et al., 2008), a need for studies on probiotic effects 
on hepatic function and blood ALT level has clearly emerged.

The main species used in propiotic products are Lactobacillus, Bifidobacterium, Enterococcus, Propionibacterium and yeasts $-S$. boulardii (Sánchez et al., 2017). The beneficial properties of probiotics are strain-dependent and must be proven, avoiding extrapolation from one strain to the other without reliable scientific evidence (Skrypnik and Suliburska, 2017). For this reason the vast majority of trials are directed at the influence of one-species probiotics on the host state. There is a relative dearth of knowledge on multispecies probiotic products, especially in terms of their cardiometabolic influence. Moreover, there is an evident lack of high-quality studies on probiotic doses exerting the most efficient cardioprotective effect. The question of whether the content of many strains in one probiotic product have additive or synergistic influence remains open.

The aim of the study was to compare the effect on body mass, liver function and lipid profile in the rat model of 6-week-long supplementation with a multispecies probiotic mixture in two doses. To the best of our knowledge, it is the first study worldwide that investigates the dose-dependence of probiotic supplementation influence on the aforementioned parameters in the case of a multi-strain product.

\section{MATERIAL AND METHODS}

\section{Animals}

Animal procedures were performed according to the approved protocols and guidelines of Poznan University of Life Sciences. The experiment conformed to the legal requirements in Poland, the European Communities Council Directive of 24 November 1986, and the National Institute of Health Guide (National Institute of Health Publications no. 80-23, Revised 1978) for the care and use of Laboratory Animals for experimental procedure. All the experimental procedures were approved by the local bioethics committee for animal studies (approval no. 24/2017). The trial was performed on male 10-week-old Wistar rats. The mean body mass of rats at the baseline of the experiment was $263 \pm 22 \mathrm{~g}$. The animals adapted to laboratory conditions for 5 days prior to the beginning of the experiment. During the adaptation period, the rats had free access to a standard diet AIN-93M (Altromin, Germany) and deionized water. The animals were housed in stainless steel cages coated with metal-free enamel throughout the adaptation period and the experiment. The rats were kept in controlled conditions - the temperature in the animal room was $21^{\circ} \mathrm{C}$, the light/dark cycles $12 \mathrm{~h}$ each and humidity $55-65 \%$ throughout the adaptation period and the experiment.

\section{Experimental design}

Thirty animals were randomized using a random number generator to three groups, 10 rats each: control group-KK, a group with a low dose of probiotic (PA) and a group with a high dose of probiotic (PB). All rats were fed a standard maintenance diet AIN-93M (Altromin, Germany) for 6 weeks. In the diet of the PA and $\mathrm{PB}$ groups, a multispecies probiotic was added in a daily dose of $2.5 \times 10^{9} \mathrm{CFU}$ and $1 \times 10^{10} \mathrm{CFU}$ respectively. The animals were allowed to eat diet and drink deionized water ad libitum throughout the experiment. The intake of diet and water was monitored daily and the rats' body mass was monitored weekly. At baseline and throughout the study there were no differences in the animals' body mass, diet intake and water intake between all three groups.

\section{Probiotic}

The multispecies probiotic mixture Ecologic Barrier (Winclove Probiotics, Amsterdam, The Netherlands) in the form of a freeze-dried powder contains 8 probiotic bacterial strains (Bifidobacterium bifidum W23, B. lactis W52, Lactobacillus acidophilus W37, L. brevis W63, L. casei W56, L. salivarius W24, Lactococcus lactis W19, Lc. lactis W58) in equal parts in a dose of $2.5 \times 10^{9} \mathrm{CFU} / \mathrm{g}$. The carrier matrix of the probiotic product is maize starch and maltodextrins (Sabico et al., 2017). This probiotic product was disseminated in the diet to receive a homogeneous mixture.

\section{Blood collection, liver collection and biochemical measurements}

At the end of the experiment, the rats were weighed and then euthanized using carbon dioxide inhalation. Blood samples were collected after $12 \mathrm{~h}$ fast by cardiac puncture in serum-separated tubes to obtain serum. 
Skrypnik, K., Bogdański, P., Łoniewski, I., Reguła, J., Suliburska, J. (2018). Effect of probiotic supplementation on liver function and lipid status in rats. Acta Sci. Pol. Technol. Aliment., 17(2), 185-192. http://dx.doi.org/10.17306/J.AFS.2018.0554

The coagulated blood was left to clot at room temperature for $30 \mathrm{~min}$, and then centrifuged for $15 \mathrm{~min}$ at $2000 \mathrm{rpm}$ at $4^{\circ} \mathrm{C}$. After centrifugation the supernatant fluid was separated and stored frozen $\left(-80^{\circ} \mathrm{C}\right)$ for analysis. During the section the internal organs, liver in this range, were removed, washed in saline, weighed and stored at $-20^{\circ} \mathrm{C}$. The serum concentrations of ALT and aspartate transaminase (AST) were measured by enzyme-linked immunosorbent assay (ELISA). The serum concentrations of TCH, HDL and TG were measured by standard commercial enzyme-linked immunosorbent assay (ELISA) in a commercial labolatory. LDL was calculated with the Friedewald equation: $\{$ Cholesterol LDL $(\mathrm{mmol} / \mathrm{L})=\mathrm{TCH}(\mathrm{mmol} / \mathrm{L})$ - HDL $(\mathrm{mmol} / \mathrm{L})-\mathrm{TG}(\mathrm{mmol} / \mathrm{L}) / 5\}$ (Friedewald et al., 1972).

\section{Statistical analysis}

Statistical analysis was performed with Statistica for Windows 10.0 (StatSoft, Kraków, Poland). The data are expressed as arithmetic means \pm standard deviation. The Shapiro-Wilk test was used to check the variables' normal distribution. Comparison between groups was carried out using one-way ANOVA analysis of variance with a Tukey's post hoc test. A $P$-value of less than 0.05 being regarded as significant.

\section{RESULTS}

Neither at baseline nor at the end of the experiment were there any differences in the body mass of rats from all three groups. The body mass of the animals at baseline and at the end of the experiment is presented in Table 1. At the completion of the study the liver mass of the rats was significantly lower in the PA and PB vs. KK group. The liver mass of the animals at the completion of the experiment is presented in Table 2.

In group PB a significantly lower serum concentration of ALT compared to the KK group was registered at the end of the trial. The serum concentrations of ALT and AST at the completion of the study are presented in Table 3.

In group PB a significantly lower serum concentration of TG compared to the KK group was registered at the end of the trial. The serum concentrations of TCH, HDL, LDL and TG at the completion of the experiment are presented in Table 4.
Table 1. Body mass of the animals at baseline and at the end of the experiment

\begin{tabular}{lccc}
\hline & & \multicolumn{2}{c}{ Body mass, $g$} \\
\cline { 3 - 4 } Group & $n$ & $\begin{array}{c}\text { mean } \pm \text { SD } \\
\text { baseline }\end{array}$ & $\begin{array}{c}\text { mean } \pm \text { SD } \\
\text { completion }\end{array}$ \\
\hline KK & 10 & $269.63 \pm 18.67$ & $383.50 \pm 22.02$ \\
PA & 10 & $260.30 \pm 25.63$ & $366.20 \pm 23.47$ \\
PB & 10 & $261.30 \pm 23.28$ & $374.20 \pm 31.13$ \\
\hline
\end{tabular}

$\mathrm{SD}$ - standard deviation.

Table 2. Liver mass of the animals at the end of the experiment

\begin{tabular}{|c|c|c|c|c|c|}
\hline \multirow{2}{*}{ Group } & \multirow{2}{*}{$n$} & \multicolumn{2}{|c|}{$\begin{array}{l}\text { Liver mass } \\
\mathrm{g}\end{array}$} & \multicolumn{2}{|c|}{$\begin{array}{c}\text { Liver mass } \\
\% \text { of total body mass }\end{array}$} \\
\hline & & mean \pm SD & median & mean $\pm \mathrm{SD}$ & median \\
\hline KK & 10 & $12.14 \pm 1.27^{\mathrm{b}}$ & 12.24 & $3.17 \pm 0.37^{b}$ & 3.23 \\
\hline PA & 10 & $10.46 \pm 1.26^{\mathrm{a}}$ & 10.26 & $2.85 \pm 0.19^{\mathrm{a}}$ & 2.83 \\
\hline PB & 10 & $10.36 \pm 1.56^{\mathrm{a}}$ & 9.71 & $2.76 \pm 0.19^{\mathrm{a}}$ & 2.69 \\
\hline
\end{tabular}

SD - standard deviation.

${ }^{\mathrm{a}, \mathrm{b}}$ Significantly different $(p<0.05)$.

Table 3. ALT and AST serum concentrations at the end of the experiment

\begin{tabular}{lcccc}
\hline \multirow{2}{*}{ Group } & \multicolumn{2}{c}{ ALT, U/L } & \multicolumn{2}{c}{ AST, U/L } \\
\cline { 2 - 5 } & mean \pm SD & median & mean \pm SD & median \\
\hline KK & $30.3 \pm 4.46^{\mathrm{b}}$ & 28.80 & $102.8 \pm 30.43$ & 95.85 \\
PA & $25.9 \pm 3.41^{\text {ab }}$ & 25.55 & $109.6 \pm 19.41$ & 108.60 \\
PB & $22.9 \pm 4.95^{\mathrm{a}}$ & 21.80 & $104.0 \pm 32.26$ & 101.70 \\
\hline
\end{tabular}

ALT - alanine transaminase, AST - aspartate transaminase, SD - standard deviation.

${ }^{\mathrm{a}, \mathrm{b}}$ Significantly different $(p<0.05)$. 
Table 4. TCH, HDL, LDL and TG serum concentrations at the end of the experiment

\begin{tabular}{lccc}
\hline & Group & Mean \pm SD & Median \\
\hline TCH, mg/dl & KK & $68.6 \pm 11.37$ & 67.20 \\
& PA & $65.7 \pm 8.00$ & 68.65 \\
& PB & $62.4 \pm 10.36$ & 59.70 \\
HDL, mg/dl & KK & $57.6 \pm 9.57$ & 57.85 \\
& PA & $57.4 \pm 5.6$ & 57.95 \\
& PB & $54.7 \pm 7.33$ & 52.70 \\
LDL, mg/dl & KK & $6.8 \pm 1.68$ & 6.65 \\
& PA & $6.8 \pm 1.29$ & 6.95 \\
& PB & $7.1 \pm 1.51$ & 6.85 \\
& KK & $143.0 \pm 33.67^{\mathrm{b}}$ & 142.00 \\
& PA, $\mathrm{mg} / \mathrm{dl}$ & $117.7 \pm 34.6^{\mathrm{ab}}$ & 113.60 \\
& PB & $107.2 \pm 45.69^{\mathrm{a}}$ & 97.90 \\
\hline
\end{tabular}

HDL - high-density lipoprotein, LDL - low-density lipoprotein, $\mathrm{TCH}$ - total cholesterol, $\mathrm{TG}$ - triglycerides, $\mathrm{SD}$ - standard deviation.

a,bSignificantly different $(p<0.05)$.

\section{DISCUSSION}

The main finding of our study is lower liver mass in both animal groups with 6-week supplementation of a multispecies probiotic compared to the group without probiotics and a lower ALT and TG serum concentration in the group with a probiotic dose of $1 \times 10^{10}$ CFU compared to the control group. This difference was not registered in the group receiving a probiotic in a dose of $2.5 \times 10^{9} \mathrm{CFU}$.

An elevated liver mass in patients not consuming alcohol results mainly from increased liver lipids accumulation and oxidative stress (Kargulewicz et al., 2010). This state, named non-alcoholic fatty liver disease, is independently associated with type 2 diabetes mellitus (DM2), obesity and metabolic syndrome, which are well proven CV risk factors. NAFLD has been determined to be a hepatic manifestation of MS (Shephard and Johnson, 2015). Serum ALT concentration is a marker of liver function increased in NAFLD.
It correlates with such states as dyslipidemia, arterial hypertension, coronary atherosclerosis and insulin resistance. Moreover, it has been proven that ALT serum activity plays the role of prognostic factor for DM2, being independent from body mass index (BMI), age, systolic blood pressure (SBP), serum TG, HDL, glucose and even alcohol consumption. Thus, there is no doubt that blood ALT level is proven to be a significant cardiometabolic risk factor (Hen et al., 2009). In our study we observed a significantly lower ALT serum concentration in the group receiving a higher dose of probiotic compared to the control group. The results of our study are in line with recent meta-analysis of 7 human double-blinded RCTs and comparative studies performed by Lavekar et al. (2017), who reported a significant reduction in blood ALT activity after probiotic supplementation in the period ranging from 2 to 7 months. Moreover, the meta-analysis of Lavekar et al. (2017) has confirmed the decrease in BMI and blood AST concentration after a probiotic is supplied. Supplementation with Lactobacillus bulgaricus and Streptococcus thermophilus have been shown to reduce not only ALT and AST, but also the gamma-glutamyltransferase (GGT) serum level in patients with NAFLD (Aller et al., 2011). Shavakhi et al. (2013) has documented amelioration of ultrasound grading of non-alcoholic steatohepatitis (NASH) after 6-month-long supplementation of a probiotic combined with metformin.

The mechanism by which probiotics ameliorate liver function remains unclear. In a study on alcoholic liver cirrhosis patients it was shown that probiotics significantly improve the blood cytokine concentration of tumor necrosis factor $\alpha(\mathrm{TNF}-\alpha)$, interleukin 6 (IL-6) and interleukin 10 (IL-10) (Loguercio et al., 2005). Moreover, probiotic bacteria lead to inhibition of the nuclear factor kappa-light-chain-enhancer of activated $\mathrm{B}$ cells $(\mathrm{NF}-\mathrm{\kappa B})$ activation (Eslamparast et al., 2014). What is more, probiotics reduce liver total fatty acids, Jun N-terminal kinase activity, fatty acid $\beta$-oxidation and mitochondrial uncoupling protein-2 expression. Thus, it seems that the hepatoprotective activity of probiotics arises mainly from their ability to modify favorably an inflammatory state and to reduce insulin resistance (Li et al., 2003). To sum up this area of our study, it can be stated that multispecies probiotic supplementation beneficially modulate the $\mathrm{CV}$ 
risk by ameliorating liver function and decreasing the serum ALT concentration.

In their meta-analysis published of 12 RCTs in 2016 Sharma et al. (2016) state that probiotic interventions show no significant effect on TG blood levels. Similarly, a meta-analysis of Lavekar et al. (2017) published as recently as in 2017 failed to prove the influence of probiotic supplementation in the range of TG metabolism. However, Lavekar et al. place emphasis on the high heterogeneity of analyzed trials in this field. In our trial we registered a significantly lower serum TG concentration in the study group consuming a higher dose of probiotic mixture compared to the control group. In a study on NASH patients, Shavakhi et al. (2013) observed a decrease in TG serum concentration after 6-month-long probiotic supplementation. In their study probiotics were given concomitantly with metformin; however, after 6 months the TG serum level was lower in the group receiving probiotics with metformin compared to the group receiving a placebo with metformin (Shavakhi et al., 2013). In a study on 24 patients with NASH Wong et al. observed a significant TG hepatic content decrease as a result of probiotic supplementation (Wong et al., 2013). It is possible to hypothesize that the favorable effect of probiotics on TG metabolism results from the amelioration of liver function. Firstly, probiotics prevent bacterial overgrowth, especially small intestinal bacterial overgrowth (SIBO), which leads to increased intestinal wall permeability and high absorption of endotoxins and lipopolysaccharide (LPS) disturbing normal liver processes (Shavakhi et al., 2013). Secondly, probiotics modulate inflammation beneficially by influencing TNF- $\alpha$, IL-6, and IL-10 serum concentration, which exerts a hepatoprotective effect (Loguercio et al., 2005). Considering the fact that serum TG concentration is an important factor of CV risk, it can be stated that by registering a lower value of this parameter in the study group receiving a higher dose of multistrain probiotic supplementation compared to the control group, our trial managed to show the cardioprotective effect of this therapeutic intervention.

It can be concluded that six-week-long supplementation with a multispecies probiotic mixture exerts a favorable and dose-dependent effect on liver function and lipid profile in the rat model. Taking into consideration the great contribution of ALT and TG blood levels in CV risk, it can be stated that multispecies probiotic supplementation may have a favorable influence on cardiovascular impairments.

\section{Study limitations}

The greatest limitation of this study was the relatively short time of intervention. However, the study managed to show significant results in a period as short as 6 weeks. Moreover, healthy rats without dyslipidemia and without liver diseases were used.

\section{Study strong points}

The greatest strong point of the study is the implementation of a multistrain probiotic product and comparative mode of the trail in the range of the product dose. Moreover, our trial is the first one conducted globally that shows the independent influence of probiotics on TG serum concentration and liver mass.

\section{REFERENCES}

Aller, R., De Luis, D. A., Izaola, O., Conde, R., Gonzalez Sagrado, M., Primo, D., ..., Gonzalez, J. (2011). Effect of a probiotic on liver aminotransferases in nonalcoholic fatty liver disease patients: a double blind randomized clinical trial. Eur. Rev. Med. Pharmacol. Sci., 15, 9, 1090-1095.

Ascher, S., Reinhardt, C. (2018). The gut microbiota - an emerging risk factor for cardiovascular and cerebrovascular disease. Eur. J. Immunol., 0, 1-12. http://dx.doi. org/10.1002/eji.201646879

Bernini, L. J., Simão, A. N. C., Alfieri, D. F., Lozovoy, M. A. B., Mari, N. L., de Souza, C. H. B., ..., Costa, G. N. (2016). Beneficial effects of Bifidobacterium lactis on lipid profile and cytokines in patients with metabolic syndrome: A randomized trial. Effects of probiotics on metabolic syndrome. Nutrition, 32, 6, 716-719. http:// dx.doi.org/10.1016/j.nut.2015.11.001

Bianconi, E., Piovesan, A., Facchin, F., Beraudi, A., Casadei, R., Frabetti, F., ..., Canaider, S. (2013). An estimation of the number of cells in the human body. Ann. Hum. Biol., 40, 6, 463-471. http://dx.doi.org/10.3109/ 03014460.2013 .807878

Bischoff, S. C., Barbara, G., Buurman, W., Ockhuizen, T., Schulzke, J.-D., Serino, M., ..., Wells, J. M. (2014). Intestinal permeability - a new target for disease prevention and therapy. BMC Gastroenterol., 14, 189. http:// dx.doi.org/10.1186/s12876-014-0189-7 
Skrypnik, K., Bogdański, P., Łoniewski, l., Reguła, J., Suliburska, J. (2018). Effect of probiotic supplementation on liver function and lipid status in rats. Acta Sci. Pol. Technol. Aliment., 17(2), 185-192. http://dx.doi.org/10.17306/J.AFS.2018.0554

Collado, M. C., Rautava, S., Aakko, J., Isolauri, E., Salminen, S. (2016). Human gut colonisation may be initiated in utero by distinct microbial communities in the placenta and amniotic fluid. Sci. Rep., 6, 1, 23129. http:// dx.doi.org/10.1038/srep23129

Dinc, G., Eser, E., Saatli, G. L., Cihan, U. A., Oral, A., Baydur, H., Ozcan, C. (2006). The relationship between obesity and health related quality of life of women in a Turkish city with a high prevalence of obesity. Asia Pac. J. Clin. Nutr., 15, 4, 508-515.

Eslamparast, T., Poustchi, H., Zamani, F., Sharafkhah, M., Malekzadeh, R., Hekmatdoost, A. (2014). Synbiotic supplementation in nonalcoholic fatty liver disease: a randomized, double-blind, placebo-controlled pilot study. Am. J. Clin. Nutr., 99, 3, 535-542. http://dx.doi. org/10.3945/ajen.113.068890

Friedewald, W. T., Levy, R. I., Fredrickson, D. S. (1972). Estimation of the concentration of low-density lipoprotein cholesterol in plasma, without use of the preparative ultracentrifuge. Clin. Chem., 18, 6, 499-502.

He, X., Slupsky, C. M., Dekker, J. W., Haggarty, N. W., Lönnerdal, B. (2016). Integrated role of Bifidobacterium animalis subsp. lactis supplementation in gut microbiota, immunity, and metabolism of infant rhesus monkeys. mSystems., 1, 6, e00128-16. http://dx.doi.org/10.1128/ mSystems.00128-16

Hen, K., Bogdański, P., Pupek-Musialik, D. (2009). Wpływ regularnej aktywności fizycznej na aktywność aminotransferazy alaninowej i asparaginianowej oraz wybrane parametry biochemiczne $u$ otyłych kobiet $\mathrm{z}$ zespołem metabolicznym [Regular physical activity and its influence on alanine amino transferase]. Przegl. Kardiodiabet. / Cardio-Diabetol. Rev., 4, 1, 11-17 [in Polish].

Houghton, D., Stewart, C. J., Day, C. P., Trenell, M. (2016). Gut microbiota and lifestyle interventions in NAFLD. Int. J. Mol. Sci., 17, 4, 447. http://dx.doi.org/10.3390/ ijms 17040447

Ierardi, E., Sorrentino, C., Principi, M., Giorgio, F., Losurdo, G., Di Leo, A. (2015). Intestinal microbial metabolism of phosphatidylcholine: a novel insight in the cardiovascular risk scenario. Hepatobiliary Surg. Nutr., 4, 4, 289-292. http://dx.doi.org/10.3978/j.issn.23043881.2015.02.01

Kargulewicz, A., Stankowiak-Kulpa, H., Grzymisławski, M. (2010). Niealkoholowa stłuszczeniowa choroba wątroby - etiopatogeneza, epidemiologia, leczenie [Nonalcoholic fatty liver disease - etiopathogenesis, epidemiology, treatment]. Now. Lek., 79, 5, 410-418 [in Polish].

Kong, A. P. S., Choi, K. C., Cockram, C. S., Ho, C. S., Chan, M. H. M., Ozaki, R., ..., Chan, J. C. N. (2008).
Independent associations of alanine aminotransferase (ALT) levels with cardiovascular risk factor clustering in Chinese adolescents. J. Hepatol., 49, 1, 115-122. http://dx.doi.org/10.1016/j.jhep.2008.02.014

Kverka, M., Tlaskalová-Hogenová, H. (2017). Intestinal microbiota: facts and fiction. Dig. Dis., 35, 1-2, 139-147. http://dx.doi.org/10.1159/000449095

Lavekar, A. S., Raje, D. V., Manohar, T., Lavekar, A. A. (2017). Role of probiotics in the treatment of nonalcoholic fatty liver disease: A meta-analysis. Euroasian J. Hepato-Gastroenter., 7, 2, 130-137. http://dx.doi. org/10.5005/jp-journals-10018-1233

Li, H., Liu, W., Xie, J. (2017). Circulating interleukin-6 levels and cardiovascular and all-cause mortality in the elderly population: a meta-analysis. Arch. Gerontol. Geriatr., 73, 257-262. http://dx.doi.org/10.1016/j.archger.2017.08.007

Li, Z., Yang, S., Lin, H., Huang, J., Watkins, P. A., Moser, A. B., ..., Diehl, A. M. (2003). Probiotics and antibodies to TNF inhibit inflammatory activity and improve nonalcoholic fatty liver disease. Hepatology, 37, 2, 343-350. http://dx.doi.org/10.1053/jhep.2003.50048

Loguercio, C., Federico, A., Tuccillo, C., Terracciano, F., D’Auria, M. V., De Simone, C., Del Vecchio Blanco, C. (2005). Beneficial effects of a probiotic VSL\#3 on parameters of liver dysfunction in chronic liver diseases. J. Clin. Gastroenterol., 39, 6, 540-543.

Marteau, P., Guyonnet, D., Lafaye de Micheaux, P., Gelu, S. (2013). A randomized, double-blind, controlled study and pooled analysis of two identical trials of fermented milk containing probiotic Bifidobacterium lactis $\mathrm{CNCM}$ I-2494 in healthy women reporting minor digestive symptoms. Neurogastroenterol. Motil., 25, 4, 331-e252. http://dx.doi.org/10.1111/nmo.12078

Nicholls, S., Scherer, D. (2015). Lowering triglycerides to modify cardiovascular risk: will icosapent deliver? Vasc. Health Risk Manag., 11, 203. http://dx.doi.org/10.2147/ VHRM.S40134

Qiu, X., Zhang, M., Yang, X., Hong, N., Yu, C. (2013). Faecalibacterium prausnitzii upregulates regulatory $\mathrm{T}$ cells and anti-inflammatory cytokines in treating TNBS-induced colitis. J. Crohn's Colitis, 7, 11, e558-e568. http://dx.doi.org/10.1016/j.crohns.2013.04.002

Sabico, S., Al-Mashharawi, A., Al-Daghri, N. M., Yakout, S., Alnaami, A. M., Alokail, M. S., McTernan, P. G. (2017). Effects of a multi-strain probiotic supplement for 12 weeks in circulating endotoxin levels and cardiometabolic profiles of medication naïve T2DM patients: a randomized clinical trial. J. Transl. Med., 15, 1, 249. http://dx.doi.org/10.1186/s12967-017-1354-x 
Sánchez, B., Delgado, S., Blanco-Míguez, A., Lourenço, A., Gueimonde, M., Margolles, A. (2017). Probiotics, gut microbiota, and their influence on host health and disease. Mol. Nutr. Food Res., 61, 1, 1600240. http:// dx.doi.org/10.1002/mnfr.201600240

Sharma, S., Kurpad, A., Puri, S. (2016). Potential of probiotics in hypercholesterolemia: A meta-analysis. Indian J. Public Health, 60, 4, 280. http://dx.doi.org/10.4103/ 0019-557X.195859

Shavakhi, A., Minakari, M., Firouzian, H., Assali, R., Hekmatdoost, A., Ferns, G. (2013). Effect of a probiotic and metformin on liver aminotransferases in non-alcoholic steatohepatitis: a double blind randomized clinical trial. Int. J. Prev. Med., 4, 5, 531-537.

Shephard, R. J., Johnson, N. (2015). Effects of physical activity upon the liver. Eur. J. Appl. Physiol., 115, 1439-6327, 1-46. http://dx.doi.org/10.1007/s00421014-3031-6

Skrypnik, K., Suliburska, J. (2017). Association between the gut microbiota and mineral metabolism. J. Sci. Food Agric. http://dx.doi.org/10.1002/jsfa.8724
Tuomisto, K., Jousilahti, P., Sundvall, J., Pajunen, P., Salomaa, V. (2006). C-reactive protein, interleukin-6 and tumor necrosis factor alpha as predictors of incident coronary and cardiovascular events and total mortality. A population-based, prospective study. Thromb. Haemost., 95, 3, 511-518. http://dx.doi.org/10.1160/TH0508-0571

van den Berg, M. J., van der Graaf, Y., de Borst, G. J., Kappelle, L. J., Nathoe, H. M., Visseren, F. L. J., ..., Nathoe, H. M. (2016). Low-density lipoprotein cholesterol, non-high-density lipoprotein cholesterol, triglycerides, and apolipoprotein B and cardiovascular risk in patients with manifest arterial disease. Am. J. Cardiol., 118, 6, 804810. http://dx.doi.org/10.1016/j.amjcard.2016.06.048

Wong, V. W. S., Wong, G. L. H., Chim, A. M. L., Chu, W. C. W., Yeung, D. K. W., Li, K. C. T., Chan, H. L. Y. (2013). Treatment of nonalcoholic steatohepatitis with probiotics. A proof-of-concept study. Ann. Hepatol., 12, 2, 256-262. 